\title{
Colonic squamous cell carcinoma in ulcerative colitis: Report of a case and review of the literature
}

\author{
Huilan Cheng $M D^{1}$, Michael D Sitrin $M D^{1}$, Sateesh K Satchidanand $M D^{2}$, Jan M Novak MD ${ }^{1}$
}

H Cheng, MD Sitrin, SK Satchidanand, JM Novak. Colonic squamous cell carcinoma in ulcerative colitis: Report of a case and review of the literature. Can J Gastroenterol 2007;21(1):47-50.

Squamous cell carcinoma (SCC) is a rare neoplasm in the colorectum. A case of SCC rising from an area of squamous metaplasia in the rectum is presented in a patient with long-standing ulcerative colitis and perianal warts. This is the first report in the literature describing the evolution of squamous metaplasia in the colonic mucosa into invasive carcinoma over time. Related literature on colorectal SCC and squamous metaplasia, and their relationships with inflammatory bowel disease and human papilloma virus, is reviewed.

Key Words: Colorectal neoplasm; Human papilloma virus; Inflammatory bowel disease; Squamous cell carcinoma; Squamous metaplasia

\section{Un carcinome squameux colique dans un cas de colique ulcéreuse : Rapport de cas et analyse bibliographique}

\begin{abstract}
Un carcinome squameux colique (CSC) est un néoplasme rare du colorectum. Un cas de CSC trouvant son origine dans un foyer de métaplasie squameuse du rectum s'est manifesté chez un patient atteint d'une colite ulcéreuse de longue date et de condylomes périanaux. C'est le premier rapport publié décrivant l'évolution d'une métaplasie squameuse de la muqueuse colique en carcinome envahissant. Sont également analysées les publications connexes sur le CSC colorectal et la métaplasie squameuse, de même que sur leur relation avec les maladies inflammatoires de l'intestin et le papillomavirus.
\end{abstract}

\section{CASE PRESENTATION}

A 51-year-old Caucasian woman presented with a 17-year history of ulcerative colitis (UC). At initial presentation in 1987, the disease involved her rectum, sigmoid, descending and transverse colon. She became steroid-dependent three years after the onset of the disease. She was unable to tolerate doses of prednisone below $20 \mathrm{mg}$ per day due to recurrence of bloody diarrhea and tenesmus. She refused proctocolectomy on numerous occasions. 6-Mercaptopurine was tried on two occasions, but she was unable to tolerate it due to the development of leukopenia. Rectal preparations, including mesalamine and steroids, did not improve her symptoms. She was maintained on prednisone $20 \mathrm{mg}$ per day, along with 5-aminosalicylic acid $3.2 \mathrm{~g}$ a day and various doses of diphenoxylate and atropine (Lomotil, Pfizer Canada Inc) over the past 14 years. She did not have any evidence of primary sclerosing cholangitis, eye inflammation, skin or joint symptoms or other extraintestinal manifestations of UC. She did not have any perianal disease during the course of her UC. Serial colonoscopies over the past 17 years consistently showed left-sided mucosal inflammation, but random biopsies of grossly normal-looking mucosa from the right colon also showed chronic inflammation with cryptitis. In 1997 (10 years after the onset of UC), a colonoscopy showed inflamed and granular rectal mucosa, and a biopsy obtained from a nodular inflamed area at $10 \mathrm{~cm}$ above the anal verge showed squamous metaplasia with parakeratosis. The pathological features were similar to those seen in condyloma or human papilloma virus (HPV)-related squamous atypia: acanthosis, nuclear enlargement with pyknosis and hyperchromasia, folded irregular nuclear membranes (raisinoid nuclei), perinuclear cytoplasmic vacuolation (koilocytosis) and multinucleated cells. The patient again refused proctocolectomy. During follow-up colonoscopies in 2000 and 2002, the segment of rectal mucosa just above the dentate line grossly appeared white and smooth, similar to squamous epithelium, and had a distinct demarcation from the proximal pink colonic mucosa (Figure 1). Biopsies from this area showed squamous metaplasia and variable degrees of dysplasia, with immature basaloid cells with mitotic figures replacing the normal epithelium (Figures 2 and 3). Another surveillance colonoscopy in 2004 (seven years after the initial diagnosis of the squamous metaplasia in her rectum and 17 years after the onset of UC) showed a $2 \mathrm{~cm}$ ulcer in the rectum at the junction of the squamous metaplastic and columnar mucosa, $8 \mathrm{~cm}$ above the dentate line (Figure 4). There were no perianal lesions at that time and the anal canal appeared normal. Biopsy of this ulcer showed squamous cell carcinoma (SCC) arising in an area of active colitis (Figure 5); invasion could not be ruled out. Computed tomography scan of the chest, abdomen and pelvis did not show any distant metastases. The patient was finally convinced to undergo total proctocolectomy. The resected specimen revealed invasive nonkeratinizing carcinoma with basaloid features; the tumour size was $1.1 \mathrm{~cm} \times 1.3 \mathrm{~cm} \times 0.7 \mathrm{~cm}$, and it invaded the muscularis propria through the inner circular layer to the longitudinal layer. The tumour extended to $1.7 \mathrm{~cm}$ from the surgical line of resection. Lymph-vascular space

\footnotetext{
${ }^{1}$ Department of Medicine, Division of Gastroenterology, Hepatology and Nutrition; ${ }^{2}$ Department of Pathology, State University of New York at Buffalo, New York, USA

Correspondence: Dr Jan M Novak, Erie County Medical Centre, 462 Grider Street, New York 14215, USA. Telephone 716-898-3391, fax 716-898-5876, e-mail jannovak@acsu.buffalo.edu 


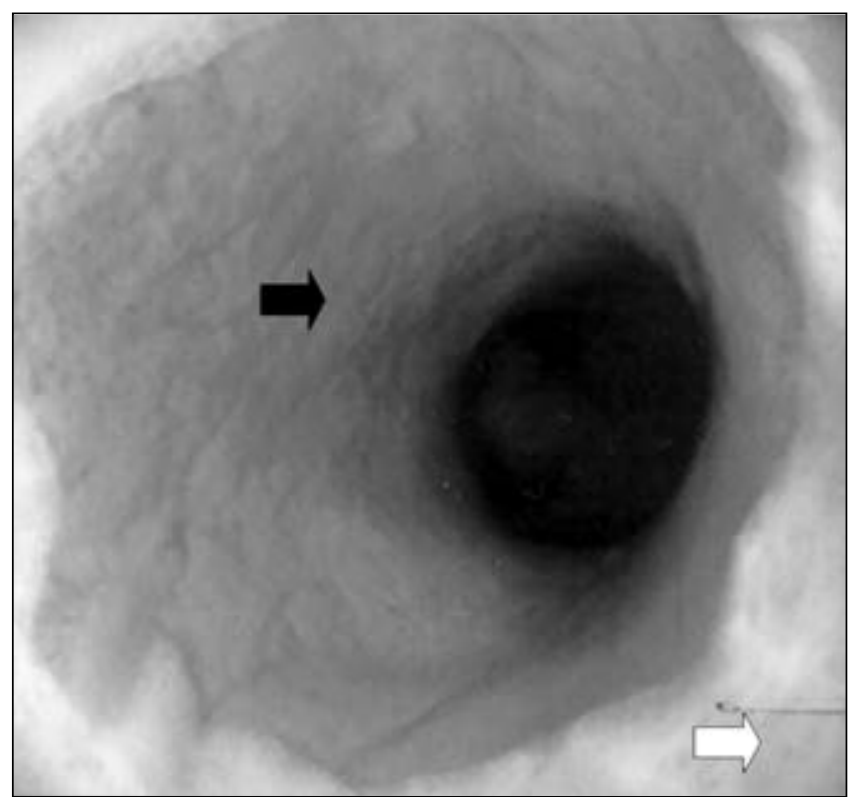

Figure 1) Colonoscopy in 2000. Junction of inflamed columnar mucosa (black arrow) and squamous metaplasia (white arrow) in the rectum

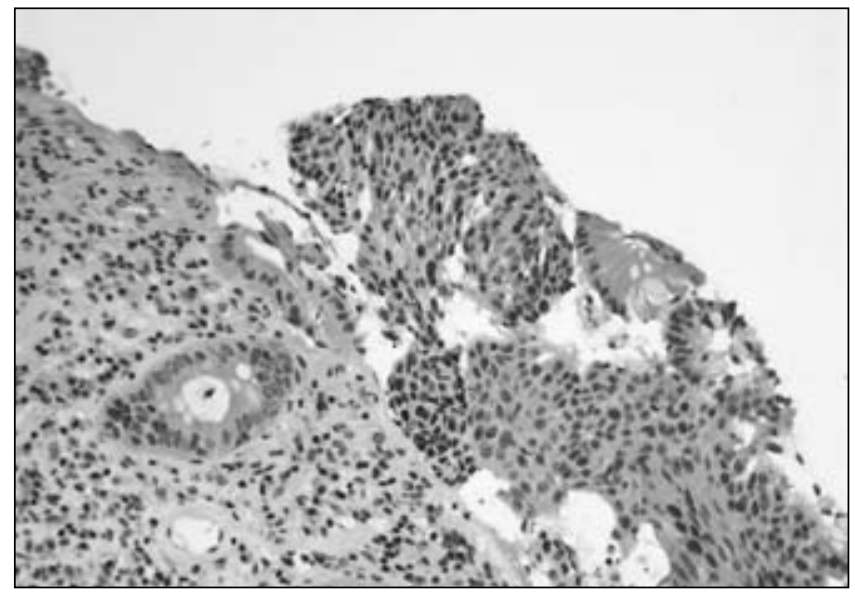

Figure 2) Pathology in 2000. Hematoxylin and eosin stain of biopsy obtained from rectal mucosa, showing glandular epithelium (left) and squamous epithelium (right), original magnification $\times 20$

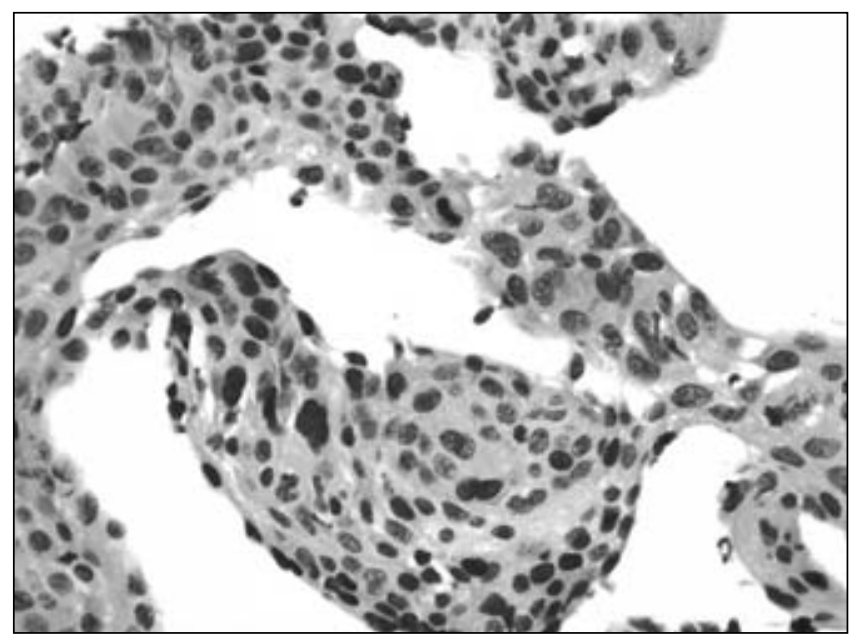

Figure 3) Pathology in 2000. High power of hematoxylin and eosin stain of biopsy obtained from rectal mucosa in 2000, showing enlarged atypical nuclei in the metaplastic areas, original magnification $\times 80$

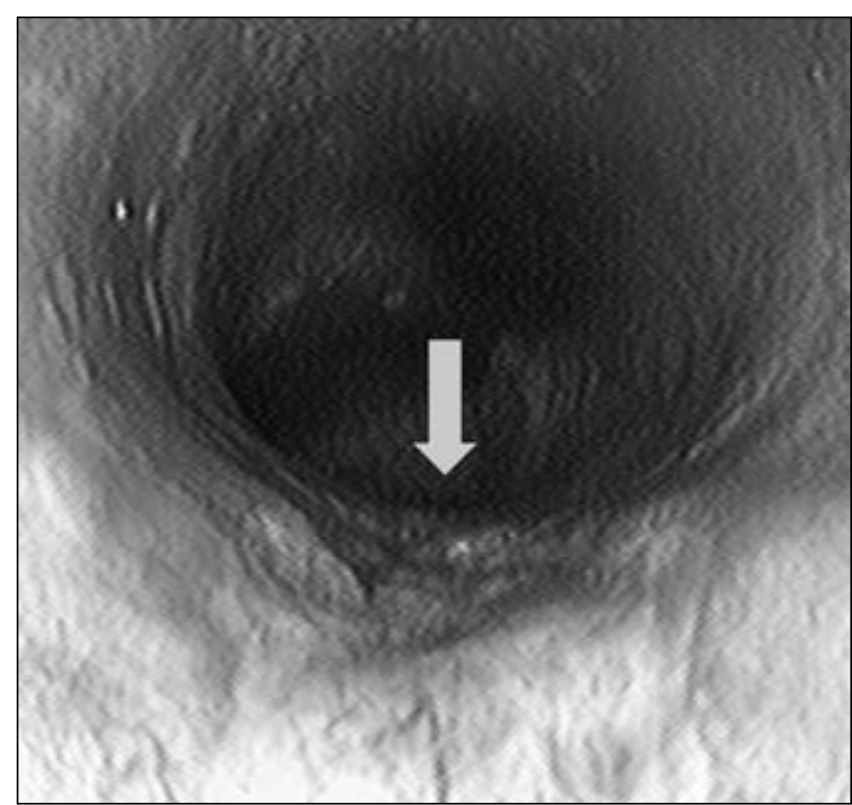

Figure 4) Colonoscopy in 2004. A $2 \mathrm{~cm}$ ulcer (arrow) at the junction of squamous metaplasia and columnar mucosa

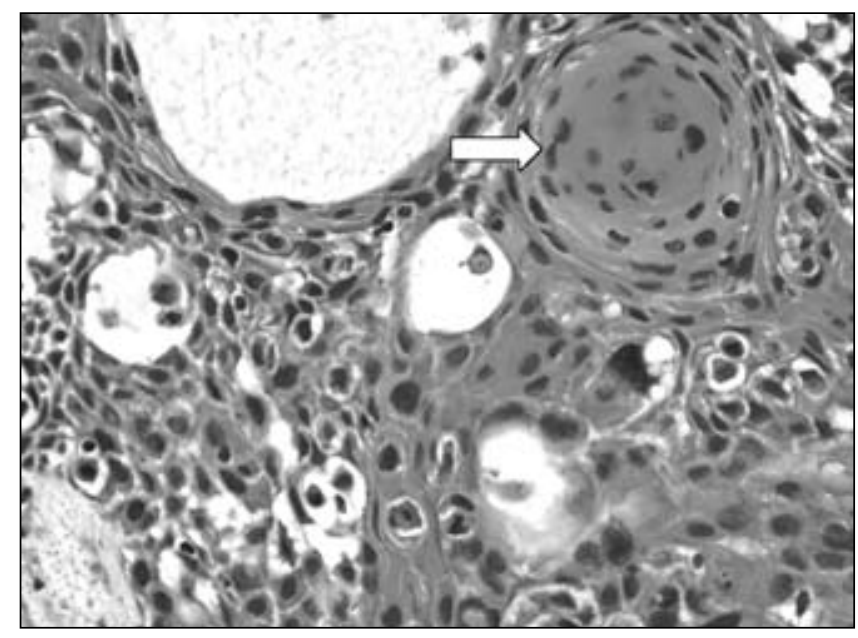

Figure 5) Pathology in 2004. High power hematoxylin and eosin stain of biopsy obtained from the rectal ulcer, showing squamous cell carcinoma with a 'keratin pearl' (arrow) and elongated nuclei, original magnification $\times 80$

invasion was present, and one of two grossly normal-appearing lymph nodes was found to have metastatic disease. On immunohistochemical staining, the tumour was positive for epithelial growth factor receptor, but was indeterminate for HPV. Inflammatory cellular reaction around the tumour was mild. The patient recovered uneventfully after surgery and was referred to oncology for adjuvant chemoradiation therapy.

Her past medical and surgical history was significant for perianal warts and a cervical cone biopsy. There was no family history of inflammatory bowel disease (IBD) or colorectal cancer.

\section{DISCUSSION}

Primary SCC arising from the columnar mucosa in the colon or rectum is very rare. The reported incidence is 0.25 to 0.1 per 1000 colorectal neoplasms (1). Diagnostic criteria established 
by Williams et al (2) have been widely accepted in the literature. First, no continuity should exist between the tumour and the squamous epithelium in the anal canal, so that SCC originating from the anal epithelium with proximal extension can be excluded. Second, there should be no squamous-lined fistulas involving the affected segment of rectum, because SCC can originate from squamous-lined fistulas. Third, metastases from another site must be ruled out. Adeno-SCC of the colorectum is considered a variant of the same tumour, but agreement is lacking in terms of the amount of squamous epithelium needed for the diagnosis (3). The largest series reported to date (4) reviewed 44 cases from the Mayo Clinic (USA) registry between 1907 and 1992, and additional cases from the literature. This study excluded lesions located within $8 \mathrm{~cm}$ of the dentate line; only tumours in the colon and proximal rectum were included. Eleven of the 44 Mayo Clinic cases reviewed were purely SCC, and two cases were associated with UC. None of the adeno-SCC in this series occurred in the setting of IBD. The study did not show any association of colorectal SCC with HPV as assessed by in situ hybridization. Gelas et al (5) reviewed another 24 cases of primary SCC of the rectum reported in the literature. Association of these cases with IBD or HPV was not reported. Clinical symptoms and gross features of SCC-containing tumours are the same as those of patients with colorectal adenocarcinoma. Most commonly reported symptoms include rectal bleeding, abdominal pain and change in bowel habits. Diagnosis is usually made by biopsy of a mass or ulcerated lesion seen on endoscopy. The right colon seems to be more frequently affected in some, but not all series $(2,6,7)$. Chronic inflammation (IBD, amebiasis and schistosomiasis) and neoplasm in an adjacent organ (ovary, endometrium and prostate) have been reported to be associated with some colonic SCCs (4), but many cases reported in the literature did not have these coexisting conditions $(1,4,6,8)$. Most cases were treated with surgical resection, and some anecdotal experiences with adjuvant radiation and chemotherapy were also recently reported $(1,4-6,8)$.

Both squamous metaplasia and SCC have been reported as possible complications of IBD, but the number of cases is very limited. Kulaylat et al (9) reviewed 16 reported cases of SCC complicating IBD. Only one occurred in the setting of chronic Crohn's colitis, and the rest were in UC. Twenty per cent of cases were adeno-SCC, whereas the other $80 \%$ were purely SCC. The ratio of women to men was 3:1, and two-thirds of the carcinomas occurred in the rectum, including the rectal stump after abdominal colectomy $(9,10)$. Five of the 16 cases had nonmetaplastic squamous epithelium adjacent to the tumour. Whether these cases were complicated by HPV infection was not reported. It is difficult to be certain from the available data that IBD is an etiological factor in SCC of the colon. The increased number of SCCs identified in patients with IBD may be partly due to a selection bias, because this group of patients undergoes surveillance colonoscopy more frequently than the average population. Further review of larger cancer registries may help to answer this question.

Squamous metaplasia is less common than SCC, and only several isolated case reports are available in the literature (11-14). Chronic irritation or inflammation was proposed as possible predisposing factors (12), but cases have been reported in the absence of these factors. Squamous cell metaplasia with and without dysplasia has been reported in the setting of chronic UC $(11,13,14)$. Based on the coexistence of premalignant and malignant changes (dysplasia and carcinoma in situ) in the squamous epithelium adjacent to the SCC of the rectum, in one case it was suggested that squamous metaplasia is a premalignant condition (11). None of the previous reports followed the evolution of squamous metaplasia over time, and conclusions were made based on the onetime observations from biopsy or surgery. Our case is the first to report the clinical course of squamous metaplasia in a patient with chronic UC over seven years. Because the patient refused colectomy on numerous occasions, we were forced to follow the lesion in her rectum until it evolved into cancer. This provided additional supporting evidence that squamous metaplasia in the colon should be considered a premalignant lesion.

The pathogenesis of SCC remains poorly understood. Some have proposed squamous differentiation of adenomas or adenocarcinomas as a cause of SCC. Others proposed possible aberrant differentiation of uncommitted basal cells or pluripotent stem cells in response to chronic inflammatory stimulation and mucosal injury $(1,4-6)$; the resultant squamous metaplasia then undergoes a malignant change to become SCC. Our case is consistent with the latter hypothesis because squamous metaplasia preceded SCC for seven years and no adenomatous changes were seen on previous biopsies.

HPV DNA is detected in up to $90 \%$ of anal SCCs. Regarding the association of HPV and carcinoma arising from the columnar mucosa in the colorectum, studies have been performed with respect to adenocarcinoma, adeno-SCC and SCC, using either polymerase chain reaction or in situ hybridization to detect HPV genomic sequences in archived tissue, and both positive and negative results have been reported in the literature $(4,15-20)$. It was reported that transfection of HPV DNA into cultured colonic adeno-SCCs can induce squamous metaplasia (21), but there is no report in the literature that HPV causes squamous metaplasia in the rectum in vivo. However, it is well-known that HPV has a predilection to infect squamous epithelium and causes a series of premalignant and malignant changes at various locations in the human body (20). By extrapolation from knowledge of HPV biology and known HPV-associated cancers, the following characteristics have been proposed for other possible HPVassociated cancers: HPV genome present in tumour cell nuclei resulting in expression of viral oncogenes; predominantly squamous cell or basaloid pathology; occurs at sites of possible direct exposure to HPV; arises from sites where HPVassociated benign lesions are usually found; presence of serum antibodies to HPV E6 and E7 proteins; high-risk sexual practices by history; and higher incidence in immunosuppressed individuals (20). In our case, it is possible that the patient first developed squamous metaplasia in the setting of chronic UC; the squamous metaplasia was subsequently infected by HPV, which then facilitated the dysplastic changes and malignant transformation. Pathological changes of dysplasia were highly variable in the series of biopsies performed between 1997 and 2002. This suggests that either dysplastic changes in squamous metaplasia may be focal or patchy, and sampling error can occur, or as with HPV infection in the cervix, the premalignant change may regress (19). The latter is less likely because the patient developed invasive cancer two years later. The present case raises important questions regarding the appropriate management of squamous metaplasia in the colon. Should it be followed by periodic surveillance or is this an indication for surgical resection? How 
often should surveillance colonoscopy be performed? The case demonstrates that a benign nondysplastic biopsy is not totally reassuring because of the risk of sampling error. The role of HPV infection in the initiation of squamous metaplasia and/or progression to cancer is uncertain. The rarity of SCC

\section{REFERENCES}

1. Juturi JV, Francis B, Koontz PW, Wilkes JD. Squamous-cell carcinoma of the colon responsive to combination chemotherapy: Report of two cases and review of the literature. Dis Colon Rectum 1999;42:102-9.

2. Williams GT, Blackshaw AJ, Morson BC. Squamous carcinoma of the colorectum and its genesis. J Pathol 1979;129:139-47.

3. Kelsen DP, ed. Gastrointestinal Oncology: Principles and Practice. Philadelphia, Lippincott Williams \& Wilkins, 2002.

4. Frizelle FA, Hobday KS, Batts KP, Nelson H. Adenosquamous and squamous carcinoma of the colon and upper rectum. Dis Colon Rectum 2001;44:341-6.

5. Gelas T, Peyrat P, Francois Y, et al. Primary squamous-cell carcinoma of the rectum: Report of six cases and review of the literature. Dis Colon Rectum 2002;45:1535-40.

6. Michelassi F, Mishlove LA, Stipa F, Block GE. Squamous-cell carcinoma of the colon. Experience at the University of Chicago, review of the literature, report of two cases. Dis Colon Rectum 1988;31:228-35.

7. Fenoglio-Preiser CM, ed. Gastrointestinal Pathology, an Atlas and Text, 2nd edn. Philadelphia, Lippincott Williams \& Wilkins, 1999.

8. Pigott JP, Williams GB. Primary squamous cell carcinoma of the colorectum: Case report and literature review of a rare entity. J Surg Oncol 1987;35:117-9.

9. Kulaylat MN, Doerr R, Butler B, Satchidanand SK, Singh A. Squamous cell carcinoma complicating idiopathic inflammatory bowel disease. J Surg Oncol 1995;59:48-55.

10. Mir-Madjlessi SH, Farmer RG. Squamous cell carcinoma of the rectal stump in a patient with ulcerative colitis. Report of a case and review of the literature. Cleve Clin Q 1985;52:257-61.

11. Woods WG. Squamous cell carcinoma of the rectum arising in an area of squamous metaplasia. Euro J Surg Oncol 1987;13:455-8. of the colorectum makes any evidence-based conclusions difficult. More clinical experiences are needed to answer these questions, and further exploration of the pathogenesis and natural history of squamous metaplasia may also help to clarify the issue.

12. Cabrera A, Pickren JW. Squamous metaplasia and squamous-cell carcinoma of the rectosigmoid. Dis Colon Rectum 1967;10:288-97.

13. Adamsen S, Ostberg G, Norryd C. Squamous-cell metaplasia with severe dysplasia of the colonic mucosa in ulcerative colitis: Report of a case. Dis Colon Rectum 1988;31:558-62.

14. Maruoka T, Hasegawa K, Nagasako K. Squamous cell metaplasia without dysplasia of the colonic mucosa in ulcerative colitis. Gastrointest Endosc 1990;36:65-6.

15. Shroyer KR, Brookes CG, Markham NE, Shroyer AL. Detection of human papillomavirus in anorectal squamous cell carcinoma. Correlation with basaloid pattern of differentiation. Am J Clin Pathol 1995;104:299-305.

16. Shroyer KR, Kim JG, Manos MM, Greer CE, Pearlman NW, Franklin WA. Papillomavirus found in anorectal squamous carcinoma, not in colon adenocarcinoma. Arch Surg 1992;127:741-4.

17. McGregor B, Byrne P, Kirgan D, Albright J, Manalo P, Hall M. Confirmation of the association of human papillomavirus with human colon cancer. Am J Surg 1993;166:738-40; discussion 741-2.

18. Audeau A, Han HW, Johnston MJ, Whitehead MW, Frizelle FA. Does human papilloma virus have a role in squamous cell carcinoma of the colon and upper rectum? Euro J Surg Oncol 2002;28:657-60.

19. Schiffman M, Kjaer SK. Chapter 2: Natural history of anogenital human papillomavirus infection and neoplasia. J Natl Cancer Inst Monogr 2003;14-9.

20. Gillison ML, Shah KV. Chapter 9: Role of mucosal human papillomavirus in nongenital cancers. J Natl Cancer Inst Monogr 2003;57-65.

21. Kinjo T, Kamiyama K, Chinen K, Iwamasa T, Kurihara K, Hamada T. Squamous metaplasia induced by transfection of human papillomavirus DNA into cultured adenocarcinoma cells. Mol Pathol 2003;56:97-108. 


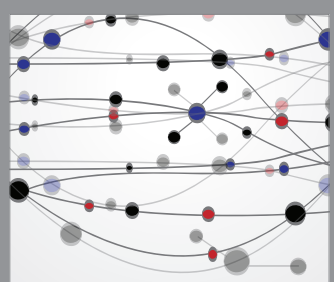

The Scientific World Journal
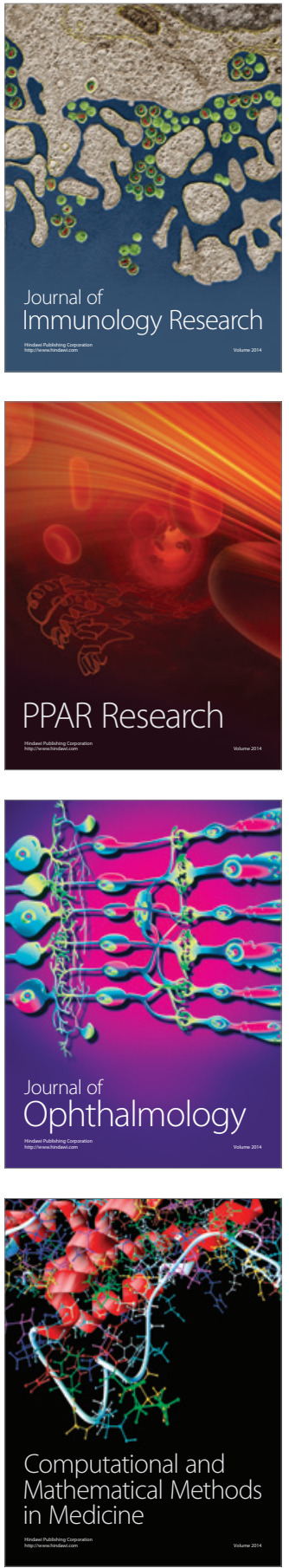

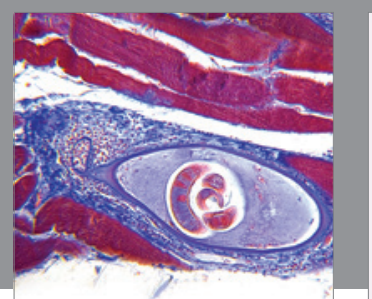

Gastroenterology Research and Practice

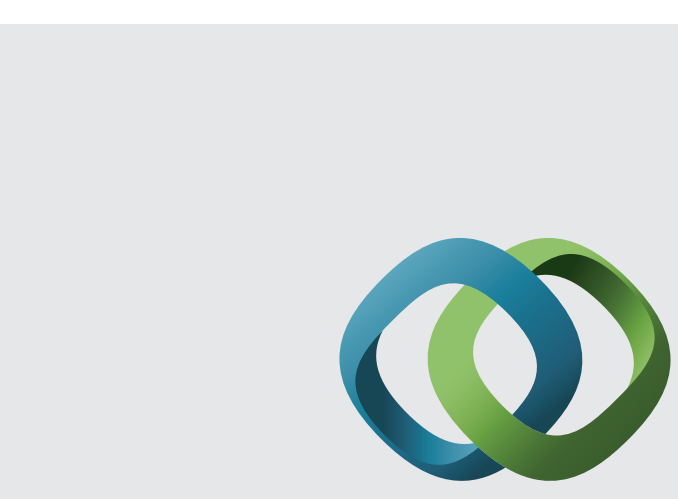

\section{Hindawi}

Submit your manuscripts at

http://www.hindawi.com
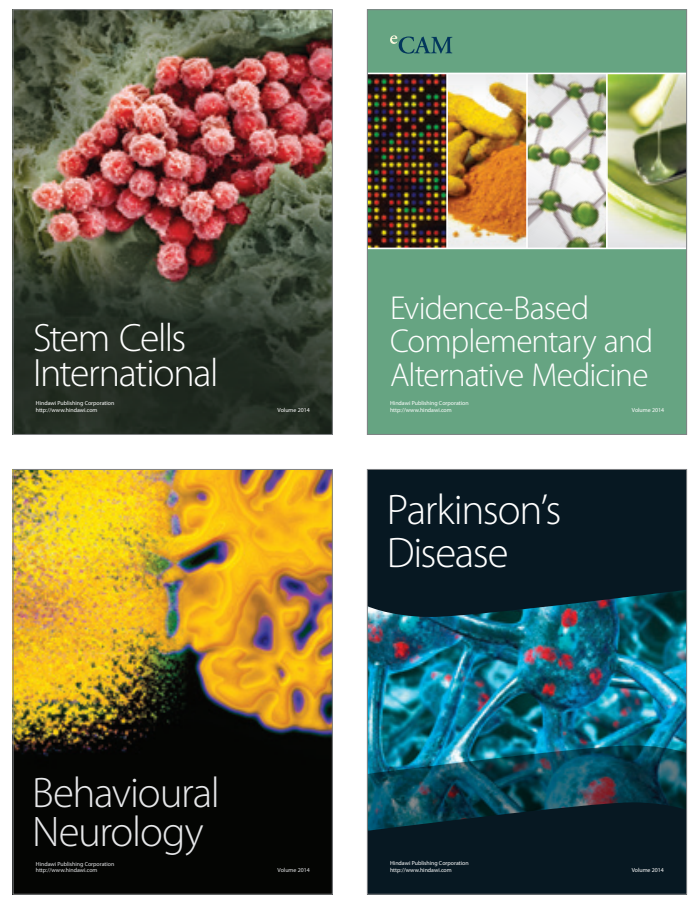
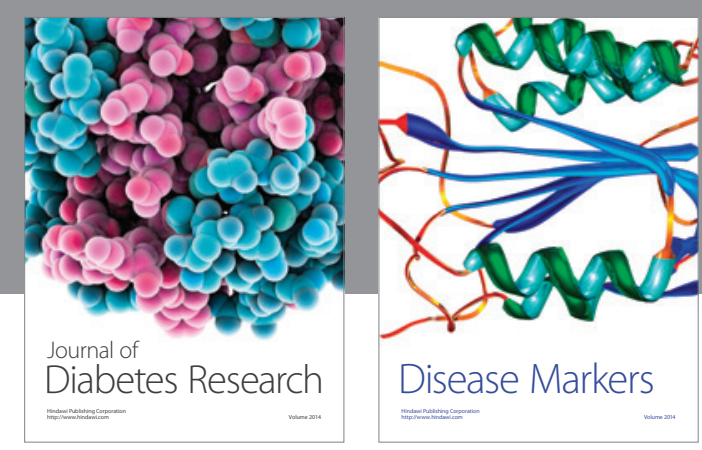

Disease Markers
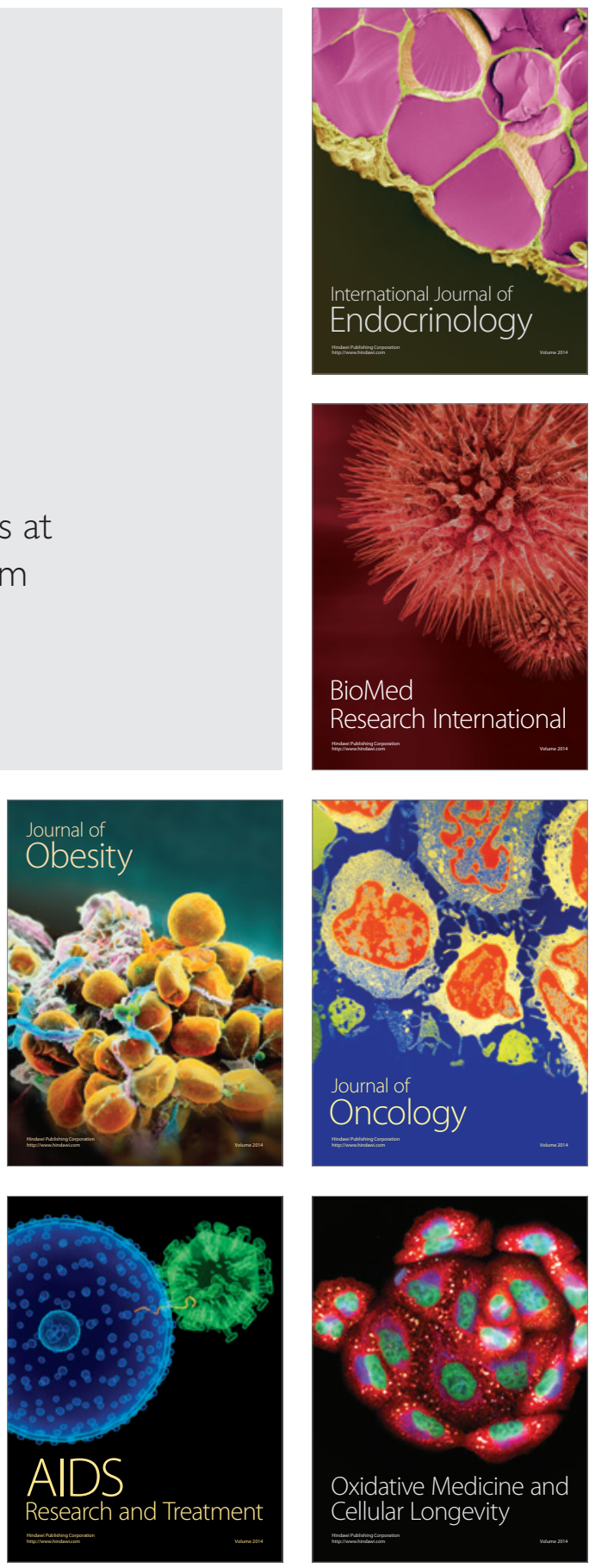